\title{
Primary malignant neoplasms of the lacrimal gland
}

\author{
John E Wright, Geoffrey E Rose, Alec Garner
}

\begin{abstract}
The clinical characteristics and outcome of $\mathbf{5 0}$ primary malignant neoplasms of the lacrimal gland are reviewed: $38(76 \%)$ adenoid cystic carcinomas, six $(12 \%)$ carcinomas arising in pleomorphic adenoma, and six (12\%) adenocarcinomas or other types of carcinoma. Most patients presented with a short history and pain, though pain tended to occur less often and later with adenocarcinoma than with adenoid cystic carcinoma. Pain was unrelated to the duration of symptoms, invasion of bone, loss of trigeminal nerve function, or the frequency and time of tumour recurrence. The estimated disease-free survival for patients with adenoid cystic carcinoma was significantly $(\mathbf{p}<0.01)$ reduced where half or more of the biopsy specimen showed basaloid differentiation. Eleven patients underwent extended cranio-orbital resection, and the others received a combination of total dacryoadenectomy and/or radiotherapy. Survival after adenoid cystic carcinomas appears to be significantly $(p<0.05)$ greater when tumour resection is combined with radiotherapy than after radiotherapy alone. At present, however, the rate of disease-free survival after treatment of adenoid cystic carcinoma appears unaltered by cranio-orbital resection, though these latter patients form a relatively greater proportion of those surviving for more than 10 years. Further long-term follow-up is needed to see if this technique does influence survival.
\end{abstract}

Primary malignant neoplasms of the lacrimal gland form $1-2 \%$ of referrals to specialist orbital clinics $^{1}$ and have a high morbidity and mortality. ${ }^{1-15}$

Previous authors have reported that the survival of patients with adenoid cystic carcinoma may be related to the histological type. ${ }^{16-18}$ However, the effect of local resection, radiotherapy, or cranio-orbital resection ${ }^{10-15}$ 18-20 $^{\text {on the fre- }}$ quency or speed of tumour recurrence remains uncertain.

The characteristics and treatment of a group of 24 patients with lacrimal gland carcinomas, grouped according to the histological classification of Foote and Frazell, ${ }^{21}$ have been previously reported from this clinic. ${ }^{15}$ For this paper, the histopathology of these 24 patients, and of a further 28 , has been reviewed and the effect of different clinical managements assessed; two of the original 24 cases were reclassified as benign lesions.

Patients and methods

Between 1968 and 1990, 50 patients attended the Orbital Clinic at Moorfields Eye Hospital with primary malignant neoplasms within the lacrimal gland; they represented less than $2 \%$ of about 3500 patients attending this specialist clinic during that period. A further patient, with an adenoid cystic carcinoma arising in an accessory lacrimal gland in the upper conjunctival fornix, is not included in this series.

Case numbers were assigned to each patient, though not in chronological order (Table 1); these correspond to those in a previous paper. ${ }^{15}$

Particular attention was given to the history. All patients underwent a complete ophthalmological examination; they were also reviewed by a neurologist, a physician, and after tissue diagnosis by an oncologist. Further investigation included orbital B-mode ultrasonography (to 1977), plain $x$-radiography of the skull or orbits, orbital venography (to 1974 ) or $x$-ray computed tomography (from 1974; 42 patients). Magnetic resonance imaging was used in a few patients to define the extent or nature of presenting or recurrent lesions.

All patients had biopsy, generally by a transseptal approach under general or local anaesthesia. In six cases the lesion was considered to be a pleomorphic adenoma and in-toto dacryoadenectomy was performed.

For the present study the histology of all cases was reviewed by one author (AG), and, where the original diagnosis was either changed or further refined, sections were also examined by Dr Ramon L Font. This review was performed without reference to the clinical presentation or outcome of the patients.

Adenocarcinoma was considered to be of primary lacrimal origin if systemic investigation for tumour was negative and if the patient did not develop another solitary clinical tumour during or after treatment of the lacrimal neoplasm.

TREATMENT METHODS FOR PRIMARY NEOPLASMS OF THE LACRIMAL GLAND

Where the symptoms were prolonged and investigations were suggestive of pleomorphic adenoma, ${ }^{22}$ the mass was removed, without prior biopsy, through a lateral orbitotomy (cases 19, $37,43,45,46,50)$. In all other cases the lesion was biopsied through a trans-septal approach, thereby maintaining intact periorbita and orbital bones.

Patients in whom the tumour was considered wholly intraorbital underwent en-bloc resection of the orbital contents and the superior and lateral orbital walls. ${ }^{123}$ At the time of surgery, however, the tumour in cases 2 and 24 was found to extend beyond the orbit.

Most patients received radiotherapy ( $>50 \mathrm{~Gy}$ ), and in some cases the bulk of tumour was resected before or after radiotherapy.

If radiotherapy had not been used as primary treatment, recurrent disease was generally 
Table 1. Details, pathology, and treatment of patients with primary malignant neoplasms of the lacrimal gland

\begin{tabular}{|c|c|c|c|c|c|c|c|}
\hline \multirow{2}{*}{$\begin{array}{l}\text { Case } \\
\text { no }\end{array}$} & \multirow{2}{*}{$\begin{array}{l}\text { Sex, } \\
\text { age }\end{array}$} & \multirow{2}{*}{$\begin{array}{l}\text { Tumour } \\
\text { type }\end{array}$} & \multicolumn{2}{|c|}{ Treatment } & \multicolumn{2}{|c|}{ Recurrence } & \multirow{2}{*}{$\begin{array}{l}\text { Follow-up } \\
\text { (years) and } \\
\text { outcome }\end{array}$} \\
\hline & & & Date & Therapy & Years & Therapy & \\
\hline 1 & F, 14 & $\mathrm{AC}$ & 1976 & $\mathrm{~L}+\mathrm{X}$ & 9 & - & 13, Dead ${ }^{\star}$ \\
\hline 2 & $M, 32$ & AC & 1976 & $\mathrm{O}+\mathrm{X}$ & 2 & $\mathrm{x}$ & 4, Dead \\
\hline 3 & $\mathrm{~F}, 17$ & $\mathrm{AC}$ & 1974 & $\mathrm{x}$ & 1 & $\mathrm{x}+\mathrm{C}$ & 2, Dead \\
\hline 4 & $\mathrm{~F}, 51$ & AC & 1974 & $\mathrm{x}$ & 1 & $\mathrm{~L}$ & 3, Dead \\
\hline 5 & F, 29 & $\mathrm{AC}$ & 1976 & $\mathrm{O}+\mathrm{X}$ & $<1$ & - & 2, Dead \\
\hline 6 & $M, 64$ & $M M$ & 1977 & $\mathrm{~L}+\mathrm{X}$ & 1 & - & 2, Dead \\
\hline 7 & $M, 49$ & & 1976 & $\underset{\mathrm{X}}{\mathrm{O}}$ & 2 & 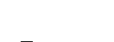 & 13, Dead * \\
\hline$[\stackrel{\circ}{9}$ & $M, 64$ & & \multicolumn{5}{|c|}{ NOW RECLASSIFIED AS PLEOMORPHIC ADENOMA] } \\
\hline 10 & $\mathrm{~F}, 57$ & AC & 1980 & $\mathrm{X}$ & 1 & - & 2, Dead \\
\hline 11 & $M, 20$ & $\mathrm{AC}$ & 1980 & $\mathrm{x}$ & 1 & - & 2 , Dead \\
\hline 12 & $M, 51$ & $\mathrm{AC}$ & 1972 & $x+0$ & & & 15, Dead $^{\star}$ \\
\hline 13 & $M, 14$ & S & 1975 & $\mathrm{~L}+\mathrm{X}$ & & & 15, Alive \\
\hline 14 & $M, 55$ & $\mathrm{AC}$ & 1974 & 0 & & & 16, Alive ${ }^{\star}$ \\
\hline 15 & $M, 41$ & AC & 1979 & $\mathrm{x}$ & 1 & C & 1, Dead \\
\hline 16 & $F, 67$ & AC & 1974 & $\mathrm{X}+\mathrm{L}$ & & & 16, Alive ${ }^{\star}$ \\
\hline 17 & $\mathrm{~F}, 14$ & $\mathrm{AC}$ & 1975 & $\mathrm{X}$ & $<1$ & - & 1 , Dead \\
\hline 18 & $M, 72$ & AC & 1979 & $\hat{\mathbf{x}}$ & 1 & - & 2, Dead \\
\hline 19 & F, 68 & AC & 1974 & $\mathrm{~L}$ & & & 6, Dead \\
\hline 20 & F, 28 & AC & 1981 & $\mathrm{~L}+\mathrm{X}$ & & & $<1$, Alive \\
\hline 21 & $M^{\prime}, 28$ & AC & 1975 & 0 & $7 \mathrm{X}$ & $14 \mathrm{C}$ & 15, Alive ${ }^{\star}$ \\
\hline 22 & F, 28 & E & 1972 & $\mathrm{~L}+\mathrm{X}$ & & & $<1$, Alive \\
\hline 23 & F, 59 & AC & \multirow{2}{*}{\multicolumn{5}{|c|}{ NOW RECLASSIFIED AS PLEOMORPHIC ADENOMA] }} \\
\hline$[24$ & $\mathbf{F}, 22$ & & & & & & \\
\hline 25 & $M, 59$ & A & 1985 & $\mathrm{x}$ & 2 & - & 3, Dead \\
\hline 26 & $\begin{array}{l}M, 38 \\
M, 62\end{array}$ & $\mathrm{~A}^{\mathrm{MM}}$ & 1989 & $\mathrm{x}^{+\mathbf{x}}$ & 1 & $\therefore$ & $\begin{array}{l}\text { 1, Allive } \\
1 \text { Alive }\end{array}$ \\
\hline 28 & $M, 45$ & A & 1989 & $\hat{\mathbf{x}}$ & 1 & - & 1 , Alive \\
\hline 29 & $M, 78$ & AC & 1982 & $\mathrm{x}$ & $<1$ & - & 1, Dead \\
\hline 30 & F, 19 & $\mathrm{AC}$ & 1977 & $\mathbf{x}$ & & & 6, Alive \\
\hline 31 & $\mathbf{F}, 17$ & AC & 1990 & $\mathbf{x}$ & & & $<1$, Alive \\
\hline 32 & $\mathbf{F}, 37$ & $\mathrm{AC}$ & 1986 & $\mathbf{x}$ & & & $<1$, Alive \\
\hline 33 & $\mathrm{M}, 8$ & $\mathrm{AC}$ & 1981 & $\mathrm{~L}+\mathrm{X}+\mathrm{O}$ & & & 7, Alive \\
\hline 34 & $M, 79$ & $\mathrm{AC}$ & 1988 & & & & $<\mathrm{l}$, Alive \\
\hline 35 & M, 29 & $\mathrm{AC}$ & 1987 & $\mathbf{x}$ & & & 3, Alive \\
\hline 36 & F, 35 & AC & 1985 & $\mathrm{~L}$ & 3 & - & 5, Alive \\
\hline 37 & $M, 34$ & AC & 1989 & $\mathrm{~L}+\mathrm{X}$ & & & 1, Alive \\
\hline 38 & M, 23 & AC & 1988 & $\mathrm{X}+\mathrm{L}$ & & & 2, Alive \\
\hline 39 & 33 & $\mathrm{AC}$ & 1989 & $\mathrm{~L}+\mathrm{X}$ & & & 1, Alive \\
\hline 40 & F, 78 & $\mathrm{AC}$ & 1989 & $\tilde{x}+\tilde{C}$ & $<1$ & - & 1, Alive \\
\hline 41 & $M, 4$ & $\mathrm{AC}$ & 1982 & $x+0$ & 3 & $\mathrm{X}$ & 6, Alive \\
\hline 42 & & $\mathrm{AC}$ & 19881 & $\mathrm{x}+\mathrm{O}$ & $<1$ & - & 2, Alive \\
\hline 43 & $F, 36$ & AC & 1987 & $\mathrm{~L}+\mathrm{X}$ & & & 3, Alive \\
\hline 44 & & $\mathrm{AC}$ & $1984 /$ & $\mathrm{x}+0$ & 4 & - & 4, Alive \\
\hline 45 & F, 59 & AC & 1989 & $\mathrm{~L}+\mathrm{X}$ & & & 1, Alive \\
\hline 46 & $M, 34$ & $\mathrm{AC}$ & 1980 & $\mathrm{~L}+\mathrm{X}$ & & & 10, Alive \\
\hline 47 & $M, 50$ & AC & 1986 & 0 & & & 4, Alive \\
\hline 48 & $M, 25$ & $\mathrm{AC}$ & 1990 & $\mathrm{x}$ & & & $<$, Alive \\
\hline 49 & $M, 35$ & MM & 1989 & $x+0$ & & & 1, Alive \\
\hline $\begin{array}{l}50 \\
51\end{array}$ & & $M M$ & 1985 & $\mathrm{~L}+\mathrm{X}$ & 3 & o & 4, Dead \\
\hline 52 & & $\begin{array}{l}M M \\
M M\end{array}$ & $\begin{array}{l}1985 \\
1985\end{array}$ & $\begin{array}{l}\mathbf{X} \\
\mathbf{X}\end{array}$ & 3 & $\overline{-}$ & $\begin{array}{l}\text { 1, Dead } \\
\text { 5, Alive }\end{array}$ \\
\hline
\end{tabular}

F, female; M, male; AC, adenoid cystic carcinoma; A, adenocarcinoma; MM, malignant mixed tumour; S, squamous carcinoma; $E$, mucoepidermoid carcinoma; $L$, localised resection of tumour; $O$, en-bloc cranio-orbital resection; $X$, radiotherapy; $C$, systemic chemotherapy.

* Denotes patients with adenoid cystic carcinomas surviving for more than 10 years.

Table 2 Patient characteristics and presenting symptoms in 48 patients with malignant neoplasms of the lacrimal gland

\begin{tabular}{lllc}
\hline Characteristic & $\begin{array}{l}\text { Adenoid cystic } \\
\text { carcinoma (38) }\end{array}$ & $\begin{array}{l}\text { Adenocarcinoma } \\
(4)\end{array}$ & $\begin{array}{c}\text { Malignant mixed } \\
\text { tumour (6) }\end{array}$ \\
\hline Sex - M:F & $21: 17$ & $4: 0$ & $5: 1$ \\
Mean age at onset of symptoms & $41(8-79)$ & $54(45-62)$ & $53(35-71)$ \\
Patients presenting at 30 years or over & $60 \%$ & $100 \%$ & $100 \%$ \\
Time from symptoms to consultation & $7 \cdot 6(0-36)$ & $5 \cdot 8(1-9)$ & $38(1-180)$ \\
(months) & $4 \cdot 4(0-33)$ & $2 \cdot 8(2-5)$ & $4(1-180)$ \\
Time from consultation to biopsy (months) & & $2(50 \%)$ & $2(33 \%)$ \\
Pain & $30(79 \%)$ & $3(75 \%)$ & $4(67 \%)$ \\
Globe displacement & $18(47 \%)$ & $4(100 \%)$ & $5(83 \%)$ \\
Mass or swelling & $19(50 \%)$ & $1(25 \%)$ & $2(33 \%)$ \\
Diplopia & $11(29 \%)$ & - & $2(33 \%)$ \\
Visual change & $9(24 \%)$ & $1(25 \%)$ & - \\
Ptosis & $6(16 \%)$ & & \\
\hline
\end{tabular}

Table 3 Frequency of radiological changes

\begin{tabular}{llcll}
\hline Radiological abnormality & & $\begin{array}{l}\text { Adenoid cystic } \\
\text { carcinoma (38) }\end{array}$ & $\begin{array}{l}\text { Adenocarcinoma } \\
\text { (4) and other } \\
\text { carcinomas (2) }\end{array}$ & $\begin{array}{l}\text { Malignant mixed } \\
\text { tumours (6) }\end{array}$ \\
\hline Erosion of bone & PF & $21 / 27(78 \%)$ & $3 / 4(75 \%)^{\star}$ & $4 / 5(80 \%)$ \\
& CT & $24 / 32(75 \%)$ & $5 / 5(100 \%)^{\star}$ & $5 / 5(100 \%)$ \\
Invasion of bone & PF & $6 / 27(22 \%)$ & $1 / 4(25 \%)$ & $2 / 5(40 \%)$ \\
Calcification of soft tissues & CT & $11 / 32(34 \%)$ & $1 / 5(20 \%)$ & $3 / 5(60 \%)$ \\
& PT & $5 / 27(19 \%)$ & $0 / 4(0 \%)$ & $0 / 5(0 \%)$ \\
& CT & $7 / 32(22 \%)$ & $3 / 5(60 \%)$ & $4 / 5(80 \%)$ \\
\hline
\end{tabular}

PF, plain $x$-rays; CT, $x$-ray computed tomography.

$\star$ Includes one squamous carcinoma; all other positive findings were in adenocarcinomas.

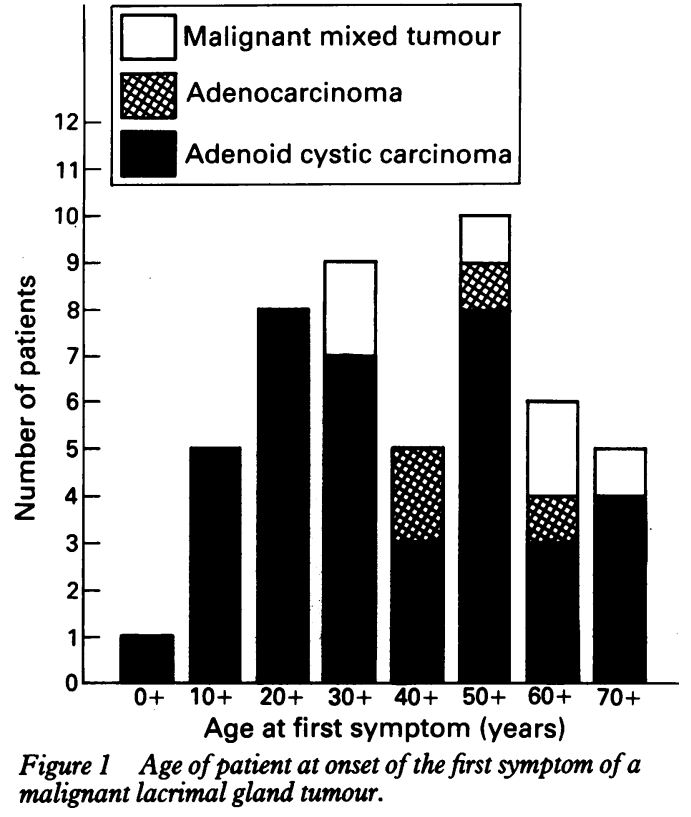

treated with this therapy. Four patients (cases 3 , $15,21,40)$ received chemotherapy for recurrent disease.

Groups were compared by analysis of variance (F), Student's $t$ test, the $\chi^{2}$ statistic, and Fisher's exact (S) test. Kaplan-Meier survival estimates were compared by the Mantel-Haenszel test.

\section{Results}

Clinical details were available for all patients, though four patients were lost to follow-up (cases $20,22,30,32$ ).

\section{EPIDEMIOLOGY}

Adenoid cystic carcinoma was most frequent ( 38 cases; $76 \%$ ), and six patients had carcinoma arising in pleomorphic adenoma ('malignant mixed tumour'), four had adenocarcinoma, one had squamous carcinoma, and one had mucoepidermoid carcinoma (Table 1). In all groups there was a preponderance of males (Table 2).

At onset of symptoms, patients with adenoid cystic carcinoma tended to be younger than those with adenocarcinoma or malignant mixed tumours (Fig 1, Table 2), though this did not reach significance at a $5 \%$ type I error $(F=1.53$, $\mathrm{p}>0 \cdot 10$ ). However, all patients presenting under 30 years of age had adenoid cystic carcinoma,

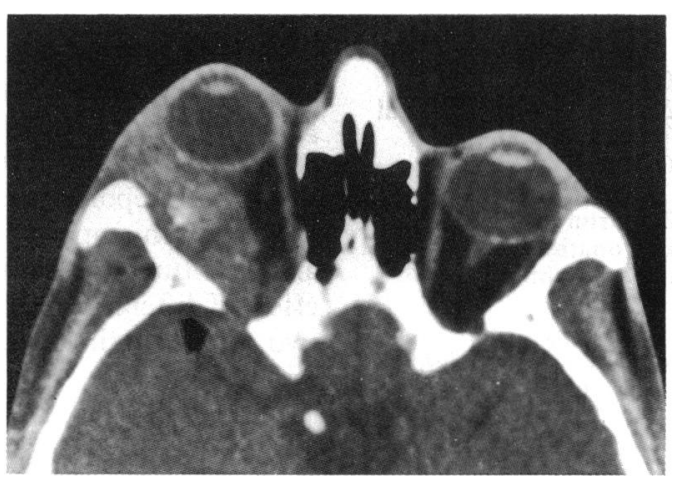

Figure 2 Orbital CT scan showing extraorbital extension of adenoid cystic carcinoma (arrow). The tumour shows a finelystippled calcification at the soft-tissue settings of this $C T$ scan. 
this proportion being significantly $(S=0 \cdot 04)$ higher than that in the older patients (Table 2). Nine $(60 \%)$ of 15 patients with basaloid adenoid cystic carcinoma presented when over 40 years of age, as compared with $8 / 23(35 \%)$ of the nonbasaloid tumours $(S=0 \cdot 15)$.

\section{SYMPTOMS}

The presenting symptoms are given in Table 2 . The mean duration of symptoms on first ophthalmic attendance was similar in patients with adenoid cystic carcinomas and adenocarcinomas (Table $2 ; t=0 \cdot 37, \mathrm{p}>0 \cdot 70$ ). However, for both adenoid cystic carcinoma $(t=4 \cdot 52$, $\mathrm{p}<0.001)$ and adenocarcinoma $(t=3.93$, $\mathrm{p}<0.05$ ), there was a significant delay between the times of first ophthalmic attendance and biopsy; that is, there was a significant delay in referral for specialist management (Table 2).

The duration of symptoms might influence outcome or treatment. However, for patients with adenoid cystic carcinoma the duration of symptoms at first ophthalmic attendance or duration at the time of biopsy were similar in 18 patients with and 20 without recurrent disease ( $p>0.40$ for 'first attendance' and $p>0.50$ for 'time of biopsy') and in 11 patients considered suitable for cranio-orbital resection or 27 cases for whom only radiotherapy and/or local resection was appropriate $(\mathrm{p}>0 \cdot 40$ and $\mathrm{p}>0 \cdot 20)$.

\section{CLINICAL SIGNS}

All 50 patients had signs of a mass in the lacrimal fossa. Ocular displacement was manifest as 2-12

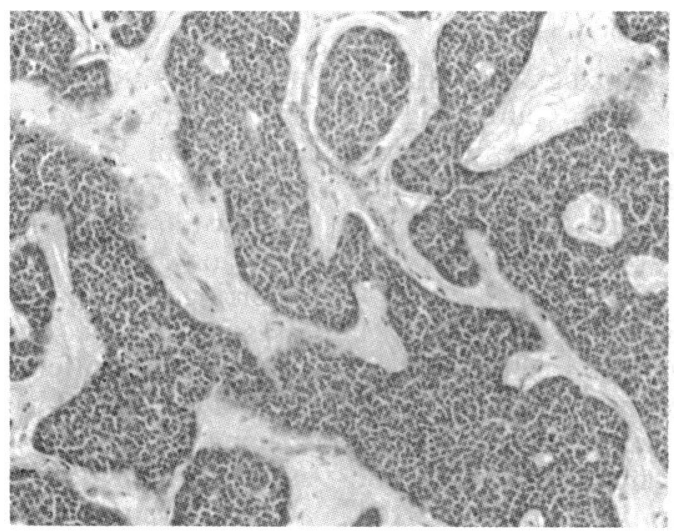

Figure 3 Adenoid cystic carcinoma: (3A) Basaloid pattern: Composed of connecting islands of compacted cells, the cells having very little cytoplasm and a superficial

resemblance to cutaneous

basal cell carcinoma. ( $3 B$ ) Cribriform pattern:

Consisting of lobules in which the cells are arranged to create multiple cystic

spaces of varying size. (3C) Sclerosing pattern: In which cords of darkly stained tumour cells are separated by interwoven bands of fibrous tissue. (3D) Tubular pattern: Where many of the tumour cells, embedded in fibrous stroma, are forming tubular structures.

(Haematoxylin and eosin $\times 90$.)

Fig $3 A$

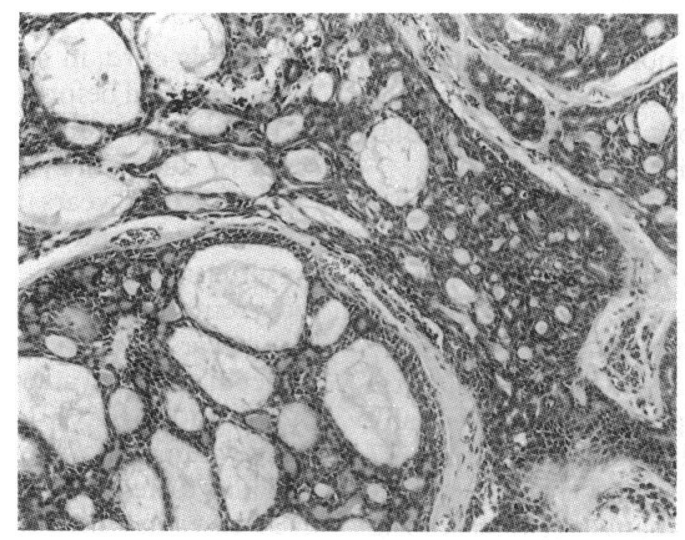

Fig $3 B$ $\mathrm{mm}$ of relative proptosis (40 patients) and inferomedial displacement of the globe (42 patients). A mass was palpable in the lacrimal fossa of 48 patients, extending superonasally in seven and inferotemporally in nine.

Generalised limitation of ocular movement, rarely conforming to a neurological paresis (cases $23,27,35$ ), was present in $40 / 49$ patients. Abnormal trigeminal nerve function, generally hypoaesthesia, was recorded in $9 / 43$ patients.

Visual acuity was reduced by two or more Snellen grades with respect to the other eye in 10/47 patients and optic disc swelling or choroidal folds were present in 12/47 cases.

\section{RADIOLOGY}

The radiological features of the three principal types of tumour are presented in Table 3 . Expansion of the lacrimal fossa was evident on $81 \%$ of the CT studies and extraorbital extension or invasion of bone in $36 \%$ (Fig 2). Calcification was detectable at soft-tissue CT window settings in $14(33 \%)$ patients and typically had a finely stippled pattern (Fig 2).

Radiologically manifest bone invasion by adenoid cystic carcinoma appears unrelated to the duration of symptoms at ophthalmic presentation $(t=1 \cdot 29, \mathrm{p}>0 \cdot 20)$.

\section{PATHOLOGY}

Review of the tumour histology resulted in the identification of $38(76 \%)$ adenoid cystic carcinomas (Figs 3A-3D), six (12\%) carcinomas which appeared to have developed within

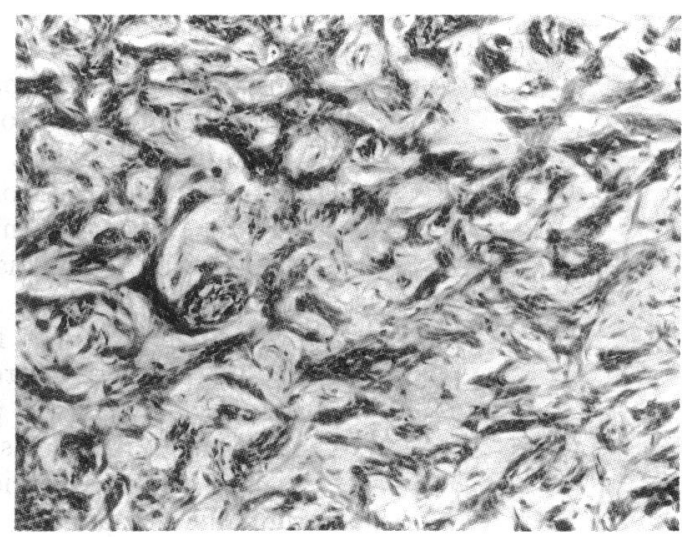

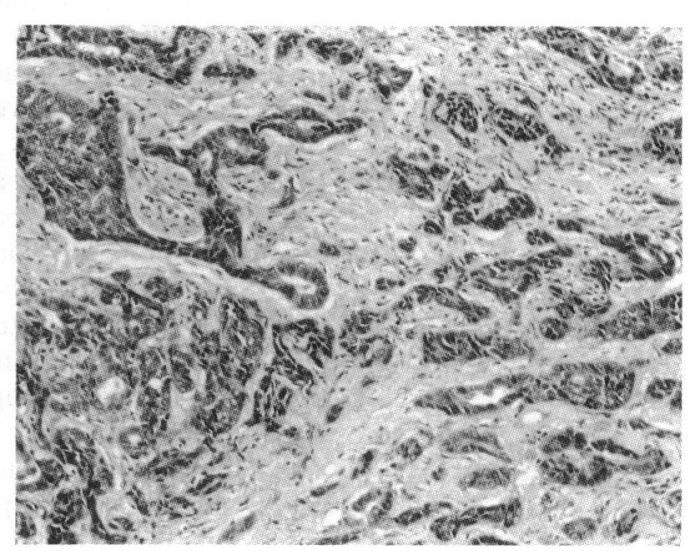

Fig $3 D$ 


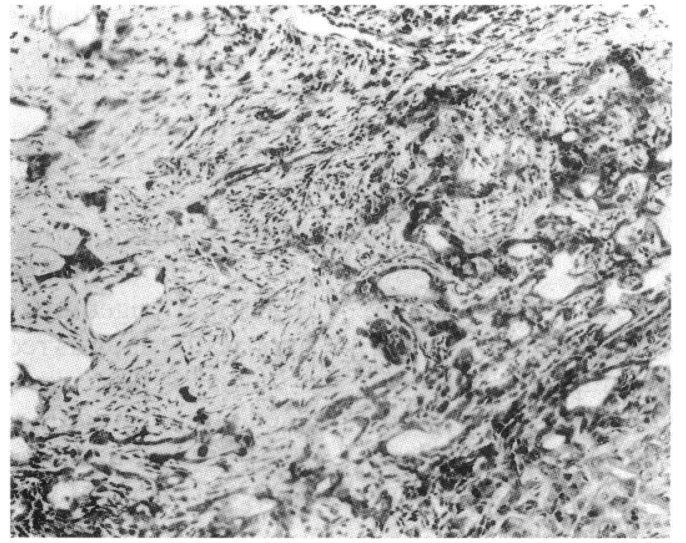

Figure 4 Carcinoma in pleomorphic adenoma (malignant mixed tumour). Infiltrative tumour, giving rise to cords and ductular forms, are superimposed on tumour with a more benign appearance. (Haematoxylin and eosin $\times 90$.)

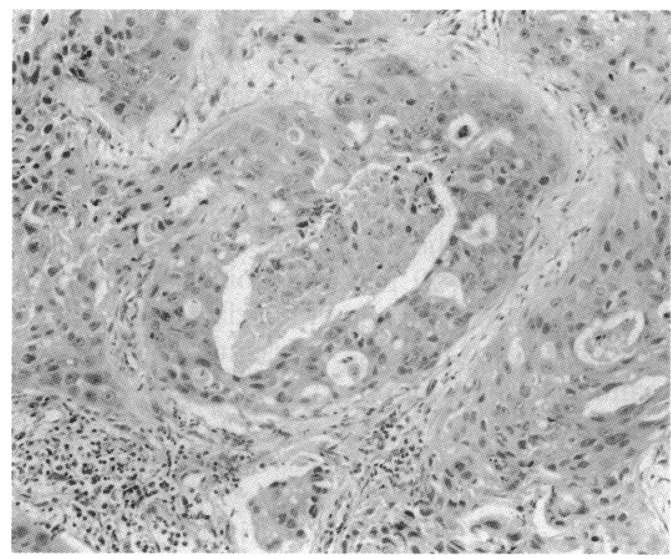

Figure 5 Adenocarcinoma: The tumour cells have abundant eosinophilic cytoplasm and are attempting to form ductules filled with inspissated cell residues and mucus. (Haematoxylin and eosin, $\times 90$.)

pleomorphic adenomas (malignant mixed tumours; Fig 4), four (8\%) pure adenocarcinomas (Fig 5), one mucoepidermoid tumour (Fig 6), and one squamous carcinoma (Fig 7). Two lesions were reclassified as pleomorphic adenomas (cases 9 and 24; Table 1).

The diagnosis was revised in 12 of the 24 patients reported on previously ${ }^{15}$ : eight tumours originally considered poorly differentiated or anaplastic carcinomas were reclassified as basaloid adenoid cystic carcinomas, and two, originally diagnosed as malignant mixed tumours, were reclassified as a mucoepidermoid carcinoma or an adenoid cystic carcinoma. Two patients (one reported previously as malignant mixed tumour, one as adenoid cystic carcinoma) were considered to have pleomorphic adenomas displaying marked, but benign, cellular pleomorphism (cases 9 and 24).

Classification as basaloid adenoid cystic carcinoma depended on finding at least half of the tumour, as seen in biopsy material, to consist of islands, or larger aggregates, of closely packed cells with hyperchromatic nuclei and scanty cytoplasm (13 cases; Fig 3A). Other histological types superimposed upon, or occasionally replacing, the more usual cribriform pattern (27 cases; Fig 3B), comprised sclerosing (eight cases; Fig 3C) or tubular changes (two cases Fig 3D).

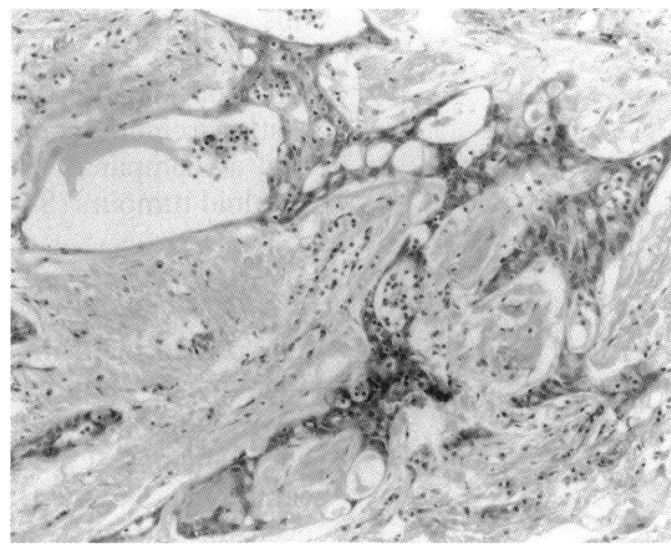

Figure 6 Mucoepidermoid tumour: Irregular cords of epidermoid cells, some including mucus-filled vacuoles, are embedded in a conspicuously mucoid structure (Haematoxylin and eosin, $\times 90$.)

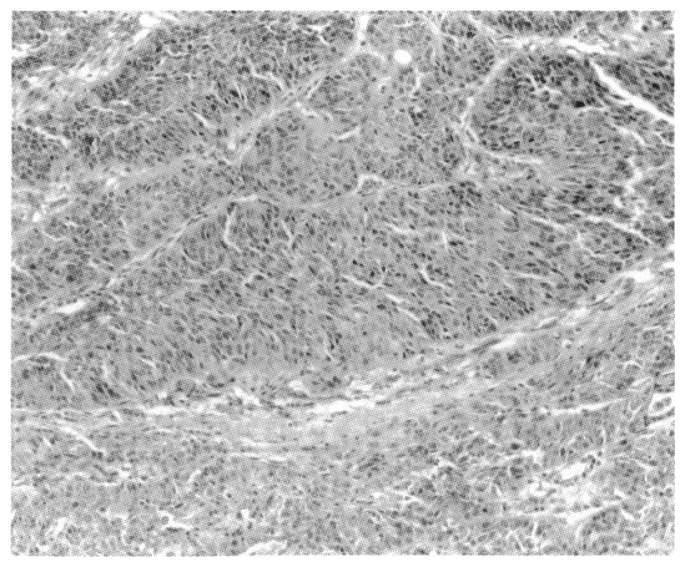

Figure 7 Squamous (epidermoid) carcinoma: Solid trabeculae of squamous epithelium are seen in the absence of mucoid elements. (Haematoxylin and eosin, $\times 90$.)

TREATMENT AND OUTCOME

The treatment and survival from its beginning are given in Table 1. Tumours recurred in the soft tissues or bones near the site of the primary tumour ( 26 cases), metastasis to regional lymph nodes or distant sites being less frequent and occurring later in the course of the disease (13 cases).

Mean survival for those who died with active tumour was similar in the three principal types of tumour (Fig 8; $F=0.07, p>0.05$ ). However, the survival time for those who died with active adenoid cystic carcinoma (mean $3 \cdot 0$, SD $3 \cdot 2$ years) was significantly less $(t=3.82, \mathrm{p}<0.01)$ than for those who died without active tumour (mean 11.4 , SD 4.8 years), implying palliation, or possibly cure, in some of the latter.

The interval before clinical evidence of tumour recurrence was similar $(t=0 \cdot 12, \mathrm{p}>0.90)$ in 16 cases of adenoid cystic carcinoma (mean $2 \cdot 2$; range $0 \cdot 2$ to $9 \cdot 3$ years) and four cases of malignant mixed tumour (mean $2 \cdot 4$; range $1 \cdot 3$ to $3 \cdot 2$ years).

Actuarial analysis suggests that the risk of recurrent adenoid cystic carcinoma continues for many years after treatment (Fig 9).

Recurrence of adenoid cystic carcinoma was significantly $(S=0.01)$ more frequent in the 13 cases where half or more of the tumour showed basaloid differentiation ( $9 / 13$ cases; $69 \%$ ), than in 23 cases in which this pattern was not evident (six recurrences; 26\%). This difference is 


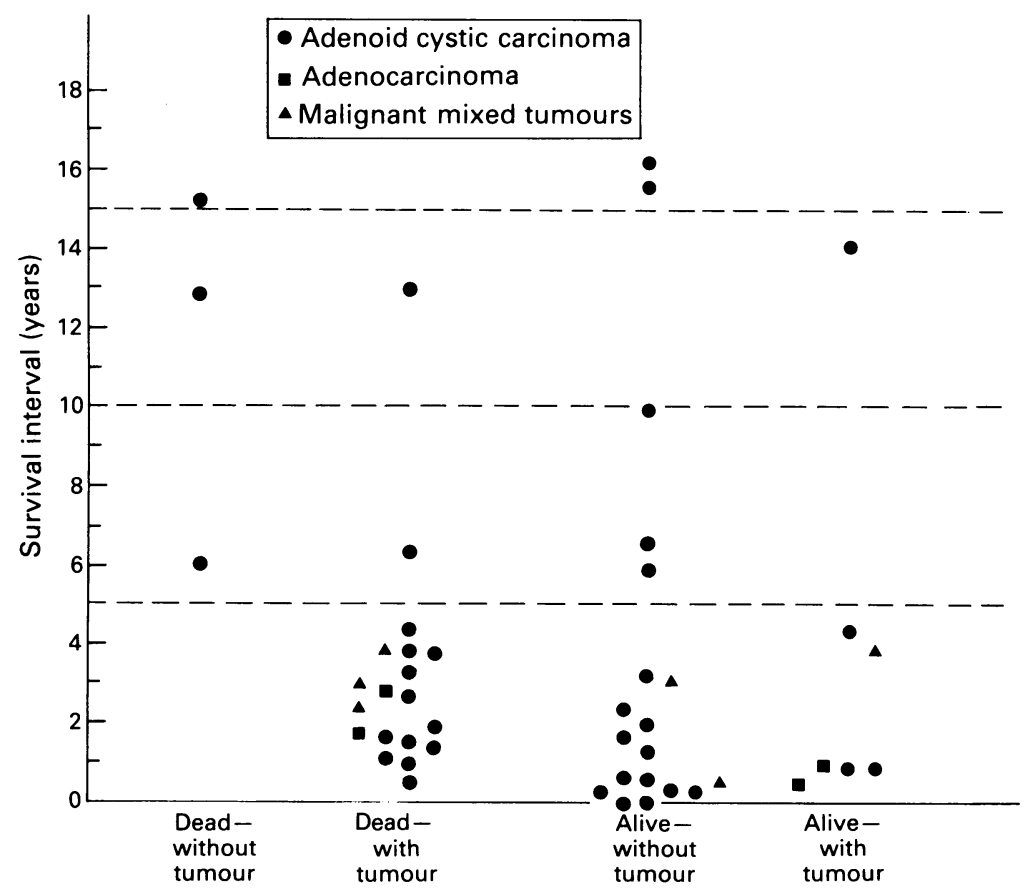

Figure 8 Survival intervals and status after first treatment of 48 patients with lacrimal gland carcinomas. A mass, both clinical and radiological, is often present after treatment. Although such a mass might contain active tumour cells, such patients are categorised as 'without tumour' until the onset of definitive signs of tumour growth. confirmed with Kaplan-Meier estimates of disease-free survival (Mantel-Haenszel statistic $=8 \cdot 31, \mathrm{p}<0.01)$, although most basaloid tumours recurred within 2 years of treatment (Fig 10).

Cranio-orbital resection does not reduce the estimated rate of recurrence of adenoid cystic carcinoma (Fig 11; Mantel-Haenszel statistic= $0 \cdot 86, \mathrm{p}>0 \cdot 05)$.

\section{Discussion}

Adenoid cystic carcinoma is, in our experience, the most common type of lacrimal gland cancer and tends to present at an earlier age than other malignant tumours at this site, having a peak incidence in the fourth decade (Fig 1). A second peak, in the sixth decade, might reflect, in the present series, a greater tendency for basaloid tumours to present after the age of 40; Milam and Heath, ${ }^{17}$ however, report basaloid tumours to occur at an earlier age than other types.

In contrast to pleomorphic adenomas, malignant lacrimal gland tumours typically present with a short history, $2:+4$ principally of pain, ocular displacement and a swelling of, or lump in, the upper lid (Table 2). Some patients with malignant mixed tumours may, however, give a long history of ocular displacement or previous surgery prior to a recent progression of symptoms. In the present series $81 \%$ of patients had symptoms for less than 1 year at first ophthalmic consultation. Delayed referral to the Orbital Clinic resulted in, on average, more than 4 months' (and up to 33 months') delay before biopsy was performed - which might adversely influence the survival of the patient.

\section{PAIN AS A SYMPTOM WITH LACRIMAL GLAND} MALIGNANCY

Pain is an important symptom of lacrimal gland malignancy ${ }^{22+4}$ and might be thought to indicate perineural infiltration with a more advanced stage of malignant disease. ${ }^{19}$

Thus, pain occurs more frequently $(S=0 \cdot 02)$, and earlier, with adenoid cystic carcinoma than with adenocarcinoma or malignant mixed tumours. However, the occurrence of pain with

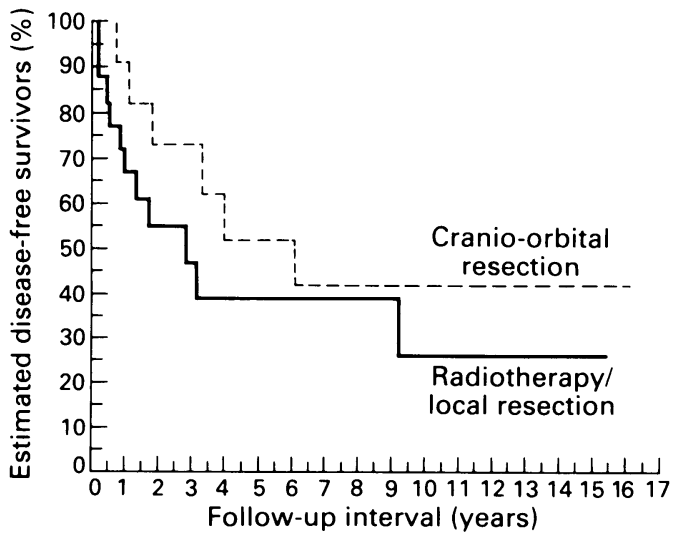

Figure 11 Kaplan-Meier estimated disease-free survival for patients with adenoid cystic carcinoma after extended orbital resection (11 cases) or limited localised therapy (radiotherapy and/or local resection; 27 cases).
Figure 10 Kaplan-Meier estimated disease-free survival for patients with adenoid cystic carcinoma where histology is either predominantly basaloid (13 cases) or non-basaloid ( 23 cases). Two cases demonstrated a minority of basaloid differentiation and, hence, could not be included in either group. 
Table 4 Survival and clinical recurrence of adenoid cystic carcinoma in 35 patients; two other patients had local resection only and one other had radiotherapy with chemotherapy

\begin{tabular}{llll}
\hline & $\begin{array}{l}\text { Radiotherapy } \\
\text { alone }(14)\end{array}$ & $\begin{array}{l}\text { Local resection and } \\
\text { radiotherapy }(10)\end{array}$ & $\begin{array}{l}\text { Cranio-orbital } \\
\text { resection, with or } \\
\text { without } \\
\text { radiotherapy }(11)\end{array}$ \\
\hline $\begin{array}{l}\text { Deaths } \\
\begin{array}{l}\text { Mean survival to date (years) } \\
\text { Interval between treatment and } \\
\text { recurrence of tumour (years) }\end{array}\end{array}$ & $\begin{array}{l}8(57 \%) \\
1 \cdot 7(0 \cdot 1-58)\end{array}$ & $\begin{array}{l}2(20 \%) \\
4 \cdot 8(0 \cdot 3-15 \cdot 4)\end{array}$ & $\begin{array}{l}5(46 \%) \\
7 \cdot 7(0 \cdot 8-16 \cdot 1)\end{array}$ \\
& $\begin{array}{l}0 \cdot 79(0 \cdot 2-1 \cdot 8) \\
(8 \text { patients) }\end{array}$ & $\begin{array}{l}6 \cdot 2(3 \cdot 1-9 \cdot 3) \\
(2 \text { patients) }\end{array}$ & $\begin{array}{l}2 \cdot 9(0 \cdot 8-6 \cdot 1) \\
(6 \text { patients) }\end{array}$ \\
\hline
\end{tabular}

adenoid cystic carcinoma is unrelated to a predominance of basaloid differentiation $(S=0 \cdot 70)$ or to the incidence $(S=0.56)$ or time $(t=0.82, \mathrm{p}>0.30)$ of recurrence. Similarly, pain is unrelated to survival intervals for all patients $(t=1.86, \mathrm{p}>0.05)$, or for those without recurrent disease $(t=1 \cdot 44, \mathrm{p}>0 \cdot 10)$. The overall duration of symptoms at ophthalmic presentation of adenoid cystic carcinoma was similar in patients with or without tumour recurrence $(t=0.72$ $\mathrm{p}>0 \cdot 40$ ), in those undergoing radiotherapy and/or local, rather than cranio-orbital, resection $(t=0.78, \mathrm{p}>0.40)$, in those with or without pain $(t=1 \cdot 46, \mathrm{p}>0 \cdot 10)$, and in those with or without invasion of bone $(t=1 \cdot 30, \mathrm{p}>0 \cdot 20)$.

Impairment of trigeminal nerve function might indicate perineural infiltration by tumour. The duration of symptoms was, however, similar in nine patients with and 33 without trigeminal sensory change $(t=0.04, \mathrm{p}>0.90)$, and the incidence of pain was similar in the groups $\mathrm{S}=0 \cdot 30$ ).

Expansion of the lacrimal fossa occurred in most patients with malignant tumours, and there was frequently radiographic evidence of bone invasion (Table 3), especially on high resolution CT. As reported by Jakobiec and others, ${ }^{25}$ lacrimal gland malignancies generally assume a more elongated, rather ill-defined mass, extending along the lateral orbital wall (Fig 2).

\section{CLINICAL OUTCOME IN RELATION TO TUMOUR HISTOPATHOLOGY}

Preoperative symptoms or signs do not provide a reliable guide to the quality or duration of relief for patients with lacrimal gland malignancy. Clear signs of extraorbital tumour invasion, such as bone destruction, inevitably increase the risk of tumour recurrence and influence management.

Tumour histopathology is the most significant factor in the survival of patients in the present series. Although patients with recurrent adenoid cystic carcinoma, adenocarcinoma, or malignant mixed tumour have similar intervals, there is considerable variation among patients with adenoid cystic carcinoma.

A preponderance of basaloid differentiation with an adenoid cystic carcinoma is associated with a highly significant $(p<0 \cdot 01)$ reduction in estimated disease-free survival (Fig 10). This difference is not due to therapeutic bias, the proportion of patients undergoing radiotherapy and/or local, rather than cranio-orbital resection, being similar $(S=0.87)$ in the basaloid and the non-basaloid groups. Likewise, the proportion of patients with pain $(S=0 \cdot 70)$ and the duration of symptoms at ophthalmic presentation $(t=0.39, \mathrm{p}>0 \cdot 60)$, or at biopsy $(t=0 \cdot 46, \mathrm{p}>0.60)$, were similar.

Without the more usual cystic morphology the solid masses of cells characteristic of basaloid adenoid cystic carcinomas might signify a less differentiated form and be consistent with a worse prognosis. A similar association has been reported with salivary gland tumours, ${ }^{26}$ though other variables (such as different anatomical sites of the glands) complicate interpretation of results. Other authors have not convincingly demonstrated these findings with salivary gland tumours. ${ }^{21}{ }^{27}$ For adenoid cystic carcinoma of the lacrimal gland Gamel and Font ${ }^{16}$ report a markedly reduced survival with basaloid differentiation (median survivals 3 and 8 years, respectively). Lee et al, ${ }^{1 /}$ while failing to confirm this, suggested that the well differentiated cribriform pattern of adenoid cystic carcinoma carries a better than average prognosis.

A tubular pattern for adenoid cystic carcinoma of the salivary glands is associated with improved prognosis, ${ }^{26}$ though this has not been shown with such tumours of the lacrimal gland. ${ }^{18}$ As in the series of Gamel and Font ${ }^{16}$ the prevalence of tumours with tubular differentiation in the present series is inadequate for such analysis.

\section{CLINICAL OUTCOME IN RELATION TO THERAPY}

Because of the small numbers, the influence of therapy on the outcome of adenocarcinoma or malignant mixed tumours is difficult to assess in the present series. However, these carcinomas appear to have a high recurrence rate within 2 to 3 years of treatment, and survival is poor (Fig 8).

Adenoid cystic carcinomas continue to recur for many years after initial treatment (Fig 9). ${ }^{1711-151819}$ With current follow-up intervals the rate of disease-free survival is not improved $(p>0.05)$ by cranio-orbital resection in those patients with clinically and radiologically localised tumours. However, the relatively high proportion of cranio-orbital resections among patients surviving for more than 10 years (Table 1) suggests that this treatment might lead to improved survival; this will be evident only with prolonged follow-up of the present cohort (for example, after another 10 years).

Twenty seven patients were regarded, on clinical and/or radiological grounds, as having adenoid cystic carcinoma extending outside the orbit or widely infiltrating orbital structures and, therefore, unsuited for cranio-orbital resection. This group received radiotherapy ( 25 cases) and/ or local resection of tumour (12 cases).

As compared with radiotherapy alone, local resection with radiotherapy for adenoid cystic carcinoma delayed significantly $(t=3 \cdot 89$, $\mathrm{p}<0.01)$ the recurrence of tumour and was associated with a slightly longer survival $(t=1.93,0.1>\mathrm{p}>0.05 ;$ Table 4). Although debulking of tumours might enhance the efficacy of radiotherapy, interpretation of the present results is difficult because of the small numbers and clinical selection of patients for treatment. However, it remains uncertain whether radiotherapy ${ }^{1+}$ affects the outcome of these malignant tumours. 
Eleven patients, considered preoperatively to be 'curable', underwent cranio-orbital resection (generally with radiotherapy) for adenoid cystic carcinoma; at surgery, however, tumour was seen to have invaded bone in two patients and was therefore possibly incurable. These 11 patients undergoing cranio-orbital resection may be compared with 10 having local resection with radiotherapy (considered beyond surgical 'cure'): tumour recurred in 6/11 patients (or 4/9, excluding those with known bone invasion) after cranio-orbital resection, as compared with $2 / 10$ after debulking and radiotherapy. Perhaps because of the small numbers, these proportions are similar $(S=0 \cdot 12)$, but so too are the survival intervals in the two groups (Table $4 ; t=1 \cdot 17$, $\mathrm{p}>0 \cdot 2$ ). Clinically apparent tumour recurrence was later after debulking and radiotherapy, but this did not reach significance (Table 4).

It is possible, therefore, that local resection of tumour with radiotherapy might be as effective as cranio-orbital resection wth radiotherapy in preventing local recurrence of malignant lacrimal gland tumours: larger numbers of patients with longer follow-up will resolve this point. Moreover, for tumours with very poor prognosis, namely adenocarcinomas and basaloid adenoid cystic carcinomas, there might be a strong case for the use of radical external beam radiotherapy or implant radiotherapy. A protocol for the future treatment of lacrimal gland carcinoma is being developed.

The authors thank Dr R L Font, for his expertise in examining many of the histopathological specimens, Dr I Moseley for his help with radiological examination and with the preparation of this paper, and Dr P N Plowman for reviewing the manuscript. We are also grateful to the many surgeons who referred cases to the Orbital Clinic and to the Department of Medical Illustration, Moorfields Eye Hospital, for clinical illustrations.

1 Rootman JA. Diseases of the orbit. A multidisciplinary approach. Philadelphia: Lippincott, 1988.

2 Godtfredsen E. Pathology of mucous and salivary gland tumours in the lacrimal gland and the relation to extraorbital mucous and salivary gland tumours (stu

3 Forrest AW. Epithelial lacrimal gland tumors: pathology as a guide to prognosis. Trans Am Acad Ophthalmol Otolaryngol guide to prognosis.
4 Ashton N. Epithelial tumours of the lacrimal gland. Mod Probl Ophthalmol 1975; 14: 306-38.

5 Zimmerman LE, Sanders TE, Ackerman LV. Epithelial tumors of the lacrimal gland: prognostic significance of histologic types. Int Ophthalmol Clin 1962; 2: 337-67.

6 Forrest AW. Pathologic criteria for effective management of epithelial lacrimal gland tumors. Am $\mathcal{f}$ Ophthalmol 1971; 71: epithelial

7 Henderson JW, Farrow GM. Orbital tumours. 2nd ed. New York: Decker, 1980.

$8 \mathrm{Ni}$ C, Cheng SC, Dryja TP, Cheng TY. Lacrimal gland tumors: a clinicopathological analysis of 160 cases. In Ophthalmol Clin 1982; 22: 99-120.

9 Perzin KH, Jakobiec FA, Livolsi VA, Desjardins L. Lacrimal gland malignant mixed tumours (carcinomas arising in benign mixed tumours): a clinicopathologic study. Cancer 1980; 45: 2593-606.

10 Byers RM, Berkeley RG, Luna $M$, Jesse RH Combined therapeutic approach to malignant lacrimal gland tumors. therapeutic approach to maligna

11 Janecka I, Housepian E, Trokel S, Rankow R, Jones I, Jakobiec $F$. Surgical management of malignant tumors of the lacrimal gland. Am F Surg 1984; 148: 539-41.

12 Font RL, Gamel JW. Epithelial tumours of the lacrimal gland: an analysis of 265 cases. In: Jakobiec FA, ed. Ocular and adnexal tumors. Birmingham: Aesculapius, 1978; 787-805.

13 Henderson JW. Adenoid cystic carcinoma of the lacrima gland, is there a cure? Trans Am Ophthalmol Soc 1987; 85 312-9.

14 Brada M, Henk JM. Radiotherapy for lacrimal gland tumours. Radiother Oncol 1987; 9: 175-83.

15 Wright JE. Factors affecting the survival of patients with lacrimal gland tumours. Can F Ophthalmol 1982; 17: 3-9.

16 Gamel JW, Font RL. Adenoid cystic carcinoma of the lacrimal gland: the clinical significance of a basaloid histologic gland: the clinical significance of a
pattern. Hum Pathol 1982; 13: 219-25.

17 Milam DF, Heath P. Primary epithelial tumours of the lacrimal gland. Am $\mathcal{F}$ Ophthalmol 1956; 41: 996-1006.

18 Lee DL, Campbell RJ, Waller RR, Ilstrup DL. A clinicopathologic study of adenoid cystic carcinoma of the lacrimal gland. Ophthalmology 1985; 92: 128-34.

9 Jackobiec FA. Tumors of the lacrimal gland and lacrimal sac In: Anderson RL, et al, eds. Symposium on diseases of the lids, lacrimal apparatus and orbit. (Trans New Orleans Acad Ophthalmol). St Louis: Mosby, 1982: 190-202.

20 Henderson JW, Neault RW. En bloc removal of intrinsic neoplasms of the lacrimal gland. Am $\mathcal{F}$ Ophthalmol 1976; 82: 905-9.

21 Foote FW, Frazell EL. Tumours of the major salivary glands. Cancer 1953; 6: 1065-133.

22 Wright JE, Stewart WB, Krohel GB. Clinical presentation and management of lacrimal gland tumours. Br $\mathcal{F}$ Ophthalmol management of

23 Cheeseman AD, Quiney RE, Wright JE. Craniofacial resection for orbital tumours. Ann R Coll Surg Engl 1989; 71: 333-7.

24 Rose GE, Wright JE. Pleomorphic adenoma of the lacrimal gland. Br F Ophthalmol 1992; 76: 395-400.

25 Jakobiec FA, Yeo JH, Trokel SL, Abbott GF, Anderson R, Citrin CM. Combined clinical and computed tomographic diagnosis of primary lacrimal fossa lesions. Am $\mathcal{F}$ Ophthalmol 1982; 94: 785-807.

26 Perzin KH, Gullane P, Clairmont AC. Adenoid cystic carcinomas arising in salivary glands: a correlation of histologic features and clinical course. Cancer 1978; 42: 26582 .

27 Skolnik EM, Friedman M, Becker S. Tumors of the major salivary glands. Laryngoscope 1977; 87: 843-61. 